\title{
The clinicopathologic characteristics and prognostic factors of gastroesophageal junction tumors according to Siewert classification
}

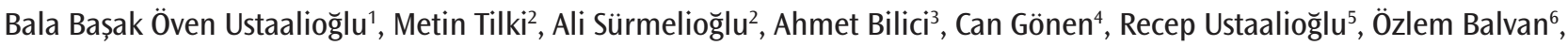
Mehmet Aliustaoğlu ${ }^{6}$

\section{ABSTRACT}

Cite this paper as:

Öven Ustaalioğlu BB, Tilki $M$, Sürmelioğlu A, Bilici A, Gönen C, Ustaalioğlu R, et al. The clinicopathologic characteristics and prognostic factors of gastroesophageal junction tumors according to Siewert classification. Turk J Surg 2017; 33(1): 18-24.

'Department of Medical Oncology, Haydarpaşa Numune Training and Research Hospital, İstanbul, Turkey

${ }^{2}$ Department of General Surgery, Haydarpaşa Numune Training and Research Hospital, ístanbul, Turkey ${ }^{3}$ Department of Medical Oncology, Medipol University School of

Medicine, İstanbul, Turkey

${ }^{4}$ Department of

Gastroenterology, Haydarpaşa

Numune Training and Research Hospital, İstanbul, Turkey

${ }^{5}$ Department of Thoracic Surgery, Siyami Ersek Thoracic and Cardiovascular Surgery Hospital, İstanbul, Turkey ${ }^{6}$ Department of Medical Oncology, Kartal Training and Research Hospital, İstanbul, Turkey

Address for Correspondence Bala Başak Öven Ustaalioğlu e-mail: basakoven@yahoo.com

Received: 20.09.2015

Accepted: 05.12.2015

@Copyright 2017

by Turkish Surgical Association
Objective: The treatment of gastroesophageal junction tumors remains controversial due to confusion on whether they should be considered as primary esophageal or as gastric tumors. The incidence of these tumors with poor prognosis has increased, thus creating scientific interest on gastroesophageal cancers. Esophagogastric cancers are classified according to their location by Siewert, and the treatment of each type varies. We evaluated the prognostic factors and differences in clinicopathologic factors of patients with gastroesophageal junction tumor, who have been treated and followed-up in our clinics.

Material and Methods: We retrospectively analyzed 187 patients with gastroesophageal junction tumors who have been operated and treated in the Oncology Department between 2005 and 2014. The chi-square test was used to evaluate differences in clinicopathologic factors among Siewert groups I, II and III. Prognostic factors were analyzed by univariate and multivariate analysis.

Results: The median age of our patients was 62 years, and approximately $70 \%$ was male. Nineteen patients (10.2\%) had Siewert I tumors, 40 (21.4\%) II, and the remaining $128(64.4 \%)$ had Siewert III tumors. Siewert III tumors were at more advanced pathologic and T stages. Preoperative chemoradiotherapy was mostly applied to Siewert group I patients. There was no difference between the 3 groups in terms of recurrence. While the median overall survival and 2-year overall survival rate were 26.6 months and $39.6 \%$, the median disease free survival and disease free survival rates were 16.5 months and $30.1 \%$, respectively. The $\mathrm{N}$ stage, pathologic stage, vascular invasion, lymphatic invasion, perineural invasion, surgical margin, and grade were associated with both overall survival and disease free survival, while pathologic stage and presence of recurrence were significant factors for overall survival. The median disease free survival for Siewert III tumors was 20 months, 11.3 month for Siewert I tumors, and 14 months for Siewert II tumors, but the finding was not statistically significant $(p=0.08)$.

Conclusion: Although gastroesophageal junction tumors were grouped according to their location and they exerted different clinicopathologic properties, their prognosis was similar.

Keywords: Esophagogastric junction, Siewert classification, prognosis

\section{INTRODUCTION}

The incidence of gastroesophageal junction (GEJ) tumors has been on a rapid upsurge in Western societies (1). Adenocarcinomas are the most frequent type within these tumors (2). Despite multimodality treatment, their prognosis is still poor with a 5-year survival rate of around 20\% (1). The issue whether they should be treated like esophageal tumors or gastric tumors remains controversial due to their location. Siewert classified these tumors into three groups according to their anatomical locations in 1996 (3). By definition, all of these tumors invade the GEJ. The classification was revised in 2000, and type I tumors were defined as tumors within 1-5 $\mathrm{cm}$ above the GEJ, type II those within $1 \mathrm{~cm}$ above and $2 \mathrm{~cm}$ below the GEJ, and type III as tumors extending 2-5 cm below the GEJ (4). This classification is clinical and is based on barium study, endoscopy, computed tomography, and intraoperative evaluation findings (5). Type I tumors are distal esophageal tumors, type II tumors are true cardiac tumors, while type III tumors are subcardial gastric tumors.

R0 resection is the most important determinant of long-term survival in GEJ tumors (6). The 5-year overall survival (OS) after R0 resection has been reported as $43.2 \%$, and those of R1 and R2 resection as $11.1 \%$ and $6.2 \%$, respectively (7). While Siewert I and II lesions are treated like esophageal tumors, Siewert III tumors are treated like gastric cancer (1). Due to screening and treatment of Barrett's esophagus, Siewert I tumors can be diagnosed at an early stage. Lymph node metastasis is another important predictor of survival, with a decrease from $53 \%$ to $11 \%$ in 5 -year OS in case of presence of lymph node metastasis (8). For this reason, lymph node dissection should be included to surgery. The rate of lymph node metastasis increases from $10 \%$ to $67 \%$ in tumors with submucosal infiltration (9). The standard surgical treatment is subtotal esophagectomy and proximal gastrectomy with the exception of endoscopic treatment at a very early stage (10, 11). Distal esophagectomy and total gastrectomy are preferred in type II tumors $(10,11)$. The standard surgical approach in type III tumors is total gastrectomy and D1 lymph node dissection (12). 
$10-20 \%$ of GEJ tumors are potentially resectable and systemic recurrence is detected in $70 \%$ despite curative surgery (13). For this reason, adjuvant, neoadjuvant chemotherapy, and chemoradiotherapy have been considered as part of treatment (14). The SWOG9008 / INT 0116 study reported that the OS was prolonged from 27 months to 36 months in gastric and GEJ tumors with postoperative chemoradiotherapy as compared to surgery alone $(p<0.005)$ (15). In this study, $21 \%$ of the patients had GEJ tumor. Another neoadjuvant study, the MAGIC study included $11.5 \%$ patients with GEJ tumors, and reported that 3 cycles of preoperative ECF (epirubicin, cisplatin, 5-FU) increased survival as compared to surgery (16). In a study involving only GEJ tumors, the overall survival was increased from 11 months to 16 months with preoperative chemoradiotherapy ( $p=0.01$ ) (17). In the German Study Group study comparing pre-operative chemoradiotherapy (CTRT) with only chemotherapy, a 3-year increase was reported in OS with preoperative CT-RT (18). Preoperative chemoradiotherapy is preferred in Siewert I and II tumors, while preoperative chemotherapy is used in type 3 tumors as in gastric tumors (19).

In our study, we evaluated the clinicopathologic features, survival rates and differences in treatment in GEJ tumors according to Siewert classification, among patients who have been treated in 3 different oncology centers in our country. We think that our study retrospectively analyzing the treatment approaches and characteristics of GEJ tumors, a group we frequently treat in oncology clinics, will reflect the approach to these tumors in our country

\section{MATERIAL AND METHODS}

We evaluated a total of 1320 patients with gastro-esophageal cancer who have been treated and followed-up in three separate oncology clinics in Istanbul between 2005 and 2014. We retrospectively analyzed 187 patients who have been operated for GEJ adenocarcinoma. Patients were classified as Siewert I, II, or III according to their endoscopic diagnosis and postoperative pathology reports. We excluded patients with other gastric and esophageal tumors. Data regarding clinicopathologic characteristics, type of surgery, additional treatments, and the survival period were extracted from patient files after obtaining written consent. The study was made according to Helsinki Declaration. The tumors were staged according to IUACC $7^{\text {th }}$ edition (20).

\section{Statistical Analysis}

We evaluated the data by using Statistical Package for the Social Sciences 17 (SPSS Inc.; Chicago, IL, USA). Categorical values were compared with chi-square and Fisher's exact test. The data are presented as median (range:). We calculated overall survival (OS) as the time from the diagnosis until the date of last observation or until the date of death. Disease-free survival (DFS) was accepted as the time when recurrence was detected or as the period between the last follow-up and the diagnosis if there was no recurrence. We evaluated the OS and DFS by the KaplanMeier method, and the survival-related factors were analyzed by the log-rank test. We analyzed independent risk factors for OS and DFS by using the COX-proportional hazard model. We considered a $p$ value $<0.05$ to be statistically significant.

\section{RESULTS}

The median age of our patients is 62 years (35-88), and approximately $70 \%$ (number: 130) was male. Total gastrectomy was performed in 144 patients (77\%), 25 of whom underwent additional distal esophagectomy. Proximal gastrectomy and distal esophagectomy was performed in the remaining 43 patients (23\%). Approximately two thirds of the patients underwent $D 1$ and $D 2$ lymph
Table 1. Clinicopathologic properties according to Siewert classification

\begin{tabular}{|lcccc|}
$\begin{array}{l}\text { Properties } \\
\text { Gender }\end{array}$ & Siewert I & Siewert II & Siewert III & $\mathbf{p}$ \\
\hline Female & $3(15.7)$ & $11(27.5)$ & $43(33.5)$ & \\
\hline Male & $16(84.3)$ & $29(72.5)$ & $85(66.5)$ & 0.2 \\
\hline Age & & & & \\
\hline 50 & $4(21)$ & $3(7.5)$ & $20(15.6)$ & \\
\hline$>50$ & $15(79)$ & $37(92.5)$ & $108(84.4)$ & 0.3 \\
\hline Histopathology & & & & \\
\hline
\end{tabular}

\section{Mucinous}

adenocarcinoma $\quad 12(63.1) \quad 30(75) \quad 100(78.1)$

$\begin{array}{lcccc}\text { Signet ring cell } & 2(10.5) & 3(7.5) & 9(7) & \\ \text { Carcinoma } & 5(26.4) & 7(17.5) & 15(11.7) & \\ \text { Mixed } & 0 & 0 & 4(3.2) & 0.4\end{array}$

\section{Lymph node dissection}

\begin{tabular}{|ccccc} 
D0 & $2(10.5)$ & $2(5)$ & $3(2.3)$ & \\
D1 & $9(47.5)$ & $11(27.5)$ & $50(39)$ & \\
\hline D2 & $4(21)$ & $16(40)$ & $50(39)$ & \\
\hline D3 & $4(21)$ & $11(27.5)$ & $25(19.7)$ & 0.001
\end{tabular}

\section{T stage}

$\begin{array}{lcccc}\text { T0 } & 1(5.2) & 0 & 0 & \\ \text { T1 } & 0 & 0 & 3(2.3) & \\ \text { T2 } & 2(10.5) & 2(5) & 35(27.3) & \\ \text { T3 } & 4(21) & 21(52.5) & 44(34.3) & \\ \text { T4 } & 12(63.6) & 17(42.5) & 46(36.1) & 0.001\end{array}$

\begin{tabular}{|lllll} 
N stage & & & & \\
N0 & $4(21)$ & $7(17.5)$ & $26(20.3)$ & \\
N1 & $3(16)$ & $5(12.5)$ & $34(26.5)$ & \\
N2 & $4(21)$ & $10(25)$ & $38(29.6)$ & \\
N3 & $8(42)$ & $18(45)$ & $30(23.6)$ & 0.1 \\
\hline
\end{tabular}

\section{Stage}

\begin{tabular}{|lcccc|}
\hline 1 & $1(5.2)$ & 0 & $12(9.3)$ & \\
\hline 2 & $3(16)$ & $9(22.5)$ & $41(32)$ & \\
\hline 3 & $11(57.8)$ & $27(67.5)$ & $72(56.2)$ & \\
\hline 4 & $4(21)$ & $4(10)$ & $3(2.5)$ & 0.006 \\
\hline LI & & & & \\
\hline Absent & $3(16)$ & $11(27.5)$ & $36(28.1)$ & \\
\hline Present & $14(73.5)$ & $29(72.5)$ & $88(68.7)$ & \\
\hline Unknown & $2(10.5)$ & 0 & $4(3.2)$ & 0.2 \\
\hline VI & & & & \\
\hline Absent & $4(21)$ & $15(37.5)$ & $37(28.9)$ & \\
\hline Present & $13(68.5)$ & $23(57.5)$ & $85(66.4)$ & \\
\hline Unknown & $2(10.5)$ & $2(5)$ & $6(4.7)$ & 0.5 \\
\hline PNI & & & & \\
\hline Absent & $5(26.3)$ & $11(27.5)$ & $32(25)$ & \\
\hline Present & $13(68.5)$ & $28(70)$ & $90(70.3)$ & \\
\hline Unknown & $1(5.2)$ & $1(2.5)$ & $6(4.7)$ & 0.9 \\
\hline
\end{tabular}




\section{Table 1. Clinicopathologic properties according to Siewert} classification (continued)

\begin{tabular}{|c|c|c|c|c|}
\hline Properties & Siewert I & Siewert II & Siewert III & $\mathrm{p}$ \\
\hline \multicolumn{5}{|l|}{ Borrmann classification } \\
\hline Type 1 (polipoid) & $1(10.2)$ & 0 & $2(1.5)$ & \\
\hline Type 2 (fungating) & 0 & $2(5)$ & $2(1.5)$ & \\
\hline Type 3 (ulcerated) & $15(73.8)$ & $33(82.5)$ & $105(82)$ & \\
\hline $\begin{array}{l}\text { Type } 4 \text { (diffuse } \\
\text { infiltrative) }\end{array}$ & $3(16)$ & $2(5)$ & $5(3.9)$ & \\
\hline Unknown & 0 & $3(7.5)$ & $14(11.1)$ & 0.1 \\
\hline \multicolumn{5}{|l|}{ Lauren classification } \\
\hline Intestinal & $4(21)$ & $9(22.5)$ & $44(34.3)$ & \\
\hline Diffuse & $3(16)$ & $2(5)$ & $27(21)$ & \\
\hline Mixed & $1(10.2)$ & $4(10)$ & $3(2.3)$ & \\
\hline Unknown & $11(52.8)$ & $25(62.5)$ & $54(42.4)$ & 0.03 \\
\hline \multicolumn{5}{|l|}{ Grade } \\
\hline 1 & 0 & 0 & $9(7.2)$ & \\
\hline 2 & $5(26.3)$ & $18(45)$ & $56(43.7)$ & \\
\hline 3 & $14(73.7)$ & $19(47.5)$ & $60(46.8)$ & \\
\hline Unknown & 0 & $3(7.5)$ & $3(2.3)$ & 0.08 \\
\hline \multicolumn{5}{|l|}{ Surgical margin } \\
\hline Positive & $4(21)$ & $15(37.5)$ & $26(20.4)$ & \\
\hline Negative & $15(79)$ & $25(62.5)$ & $102(79.6)$ & 0.08 \\
\hline \multicolumn{5}{|l|}{ Metastasis } \\
\hline Present & $6(31.5)$ & $6(15)$ & $6(4.6)$ & \\
\hline Absent & $13(68.5)$ & $34(85)$ & $122(95.4)$ & $<0.001$ \\
\hline \multicolumn{5}{|l|}{ Preoperative CT-RT } \\
\hline Present & $9(47.3)$ & $5(12.5)$ & 0 & \\
\hline Absent & $10(52.8)$ & $35(87.5)$ & $128(100)$ & $<0.001$ \\
\hline \multicolumn{5}{|l|}{ Recurrence } \\
\hline Present & $8(42.1)$ & $21(52.5)$ & $65(50.7)$ & \\
\hline Absent & $11(47.9)$ & $19(47.5)$ & $63(49.3)$ & 0.7 \\
\hline \multicolumn{5}{|l|}{ Type Of Surgery } \\
\hline Total Gastrectomy & $12(63.1)$ & $39(97.5)$ & $93(72.6)$ & \\
\hline Proximal Gastrectomy & $7(36.9)$ & $1(2.5)$ & $35(27.4)$ & 0.02 \\
\hline
\end{tabular}

LI: lymphatic invasion; VI: vascular invasion; PNI: perineural invasion;

$\mathrm{CT}$ : chemotherapy; RT: radiotherapy

Datas are presented as $\mathrm{n}(\%)$.

node dissection, and 53.7\% had D0 while $21 \%$ had D3 dissection. The median number of extracted lymph nodes was 22 (4-76), and that of metastatic lymph nodes was 4 (0-69). Pathologic stage III (58.8\%) and stage II (28.3\%) disease was more frequent with $7 \%$ stage 1 and $5.9 \%$ stage 4 disease. A total of 142 patients (75.9\%) underwent $\mathrm{R} 0$ resection. $\mathrm{R} 1$ resection was performed in the remaining 45 patients. $7.5 \%$ of patients received preoperative chemoradiotherapy, neoadjuvant 5-FU based treatment was applied to 15 patients, and adjuvant chemotherapy was applied to 162 patients (5-FU, capecitabine, CF, ECF). 124 of the patients who received adjuvant chemotherapy also received postoperative radiotherapy.

Evaluation of the differences in patient clinicopathologic features according to Siewert classification showed that a more aggressive lymph node dissection (D2, D3) was performed in Siewert II tumors
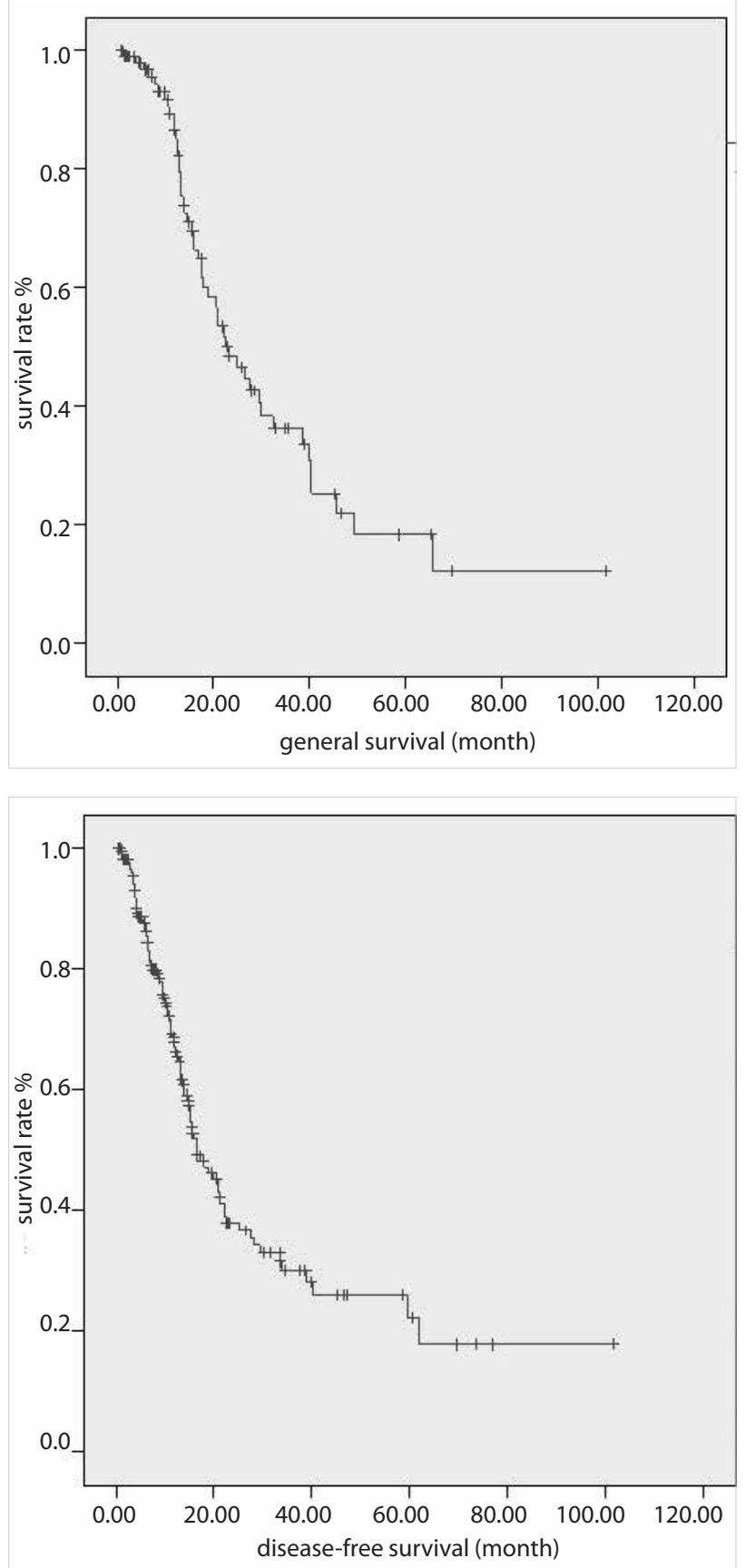

Figure 1. a, b. (a) OS curve, (b) DFS curve

Patients with Siewert I tumors were at advanced T and pathologic stages, and their metastasis detection rate was also high. Siewert III patients presented at earlier pathologic and T stages. From the surgical treatment point of view, total gastrectomy was performed more in Siewert II tumors whereas proximal gastrectomy was performed more frequently in type I and III ( $p=0.02)$. The number of patients with total gastrectomy and proximal gastrectomy within Siewert I, II and III patients was 12 and 7, 39 and 1, and 93 and 35, respectively. Distal esophagectomy was performed in 25 patients with total gastrectomy and 4 with proximal gastrectomy. The type of surgery was not associated with survival rate (Table 1).

During a median follow-up of 13.9 months, the OS and 2-year survival rates were identified as 26.6 months and $55.9 \%$, while the median DFS and 2-year DFS rates were 16.5 months and $37.9 \%$, respectively. The OS and DFS curves are shown in Figure 1 


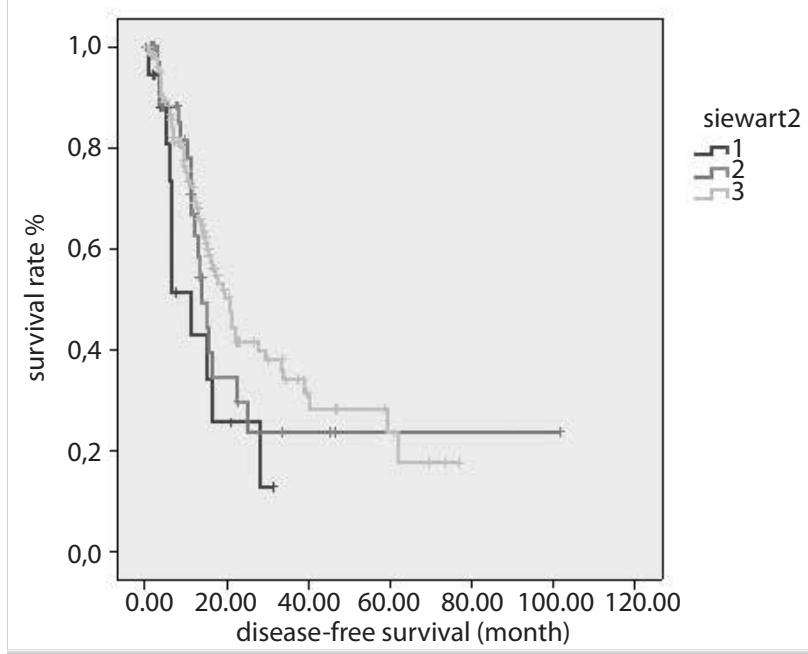

Figure 2. DFS curves according to Siewert classification
The overall survival rate of patients did not differ according to Siewert classification $(p=0.5)$, while the DFS was increased in patients with Siewert III tumors (11.3 months in Siewert I, 14 months in II, and 20.8 months in III) despite not reaching statistical significance $(p=0.08)$ (Figure 2). Recurrence was detected in 93 (49.7\%) patients, the most frequent sites being the liver, peritoneum, loco-regional, lung, bone, ovary, brain and multiple metastases. The site of recurrence did not differ among groups according to the Siewert classification. On univariate analysis; $\mathrm{N}$ stage, pathologic stage, lymphatic invasion (LI), vascular invasion ( $\mathrm{VI})$, perineural invasion (PNI), surgical margin, and grade were associated with both OS and DFS, while recurrence and histopathologic type were associated with overall survival. The results of univariate analysis are shown in Table 2. On multivariate analysis; stage, grade, and recurrence were found as independent risk factors for OS, while grade, surgical margin, and preoperative chemoradiotherapy were independent risk factors for DFS (Table 3).

Table 2. Univariate analysis results

\begin{tabular}{|c|c|c|c|c|c|c|c|c|c|}
\hline Properties & $\begin{array}{r}2 \text { yea } \\
\text { number } \mathbf{n}(\%)\end{array}$ & $\begin{array}{l}\text { r OS } \\
\text { ratio (\%) }\end{array}$ & $\begin{array}{l}\text { Median OS } \\
\text { (month) }\end{array}$ & Margin & $\mathrm{p}$ & $\begin{array}{c}2 \text { year DFS } \\
\text { ratio (\%) }\end{array}$ & $\begin{array}{l}\text { Median DFS } \\
\text { (month) }\end{array}$ & Margin & $\mathrm{p}$ \\
\hline \multicolumn{10}{|l|}{ Gender } \\
\hline Female & $57(30.5)$ & 57.5 & 33.2 & $15.7-50.6$ & & 43.8 & 21.1 & $14-28.2$ & \\
\hline Male & $130(69.5)$ & 55.1 & 24.5 & $19.7-31.1$ & 0.7 & 35.4 & 16.4 & 12.-19.9 & 0.2 \\
\hline \multicolumn{10}{|l|}{ Age } \\
\hline$\leq 50$ & $27(14.4)$ & 64.2 & 25.4 & $3.7-47$ & & 45.3 & 22.1 & $0-45.4$ & \\
\hline$>50$ & $160(85.6)$ & 54.7 & 26.6 & $20.4-37.7$ & 0.6 & 36.6 & 16.4 & 13-19.7 & 0.3 \\
\hline \multicolumn{10}{|l|}{ Histopathology } \\
\hline Adenocarcinoma & $142(75.9)$ & 57.1 & 28.7 & $21.7-35.6$ & & 40.3 & 17.9 & $13.2-22.6$ & \\
\hline Mucinous & $14(7.5)$ & 46.7 & 23.1 & $2.5-43.6$ & & 25 & 9.7 & $0-25.9$ & \\
\hline Signet ring cell & $27(14.4)$ & 53.4 & 25 & $10.3-39.6$ & & 44.7 & 15.5 & 13-17.9 & \\
\hline Mixed & $4(2.1)$ & 25 & 13 & $8.5-17.5$ & 0.04 & 0 & 11.8 & $5.6-18.1$ & 0.3 \\
\hline \multicolumn{10}{|c|}{ Lymph node dissection } \\
\hline Do & $7(3.7)$ & $\mathrm{Na}$ & & & & 85.7 & $\mathrm{Na}$ & na & \\
\hline D1 & $70(37.4)$ & 57.6 & & & & 32.9 & 16 & $11.9-20$ & \\
\hline D2 & $70(37.4)$ & 53.8 & & & & 32.4 & 16.4 & $8.4-24.3$ & \\
\hline D3 & $40(21.4)$ & 48.7 & $\mathrm{Na}$ & na & 0.1 & 43.3 & 15.4 & $1.5-29.3$ & 0.1 \\
\hline \multicolumn{10}{|l|}{ T stage } \\
\hline T0 & $(0.5)$ & $\mathrm{Na}$ & & & & & & & \\
\hline T1 & $3(1.6)$ & $\mathrm{Na}$ & & & & na & & & \\
\hline $\mathrm{T} 2$ & 39 (20.9) & 60.6 & & & & 48.1 & & & \\
\hline T3 & 69 (36.9) & 52.1 & & & & 35.4 & & & \\
\hline T4 & $175(40.1)$ & 51.9 & $\mathrm{Na}$ & na & 0.2 & 31 & $\mathrm{Na}$ & na & na \\
\hline \multicolumn{10}{|l|}{ N stage } \\
\hline NO & $37(19.8)$ & 76.8 & $\mathrm{Na}$ & na & & 60.5 & $\mathrm{Na}$ & na & \\
\hline N1 & $42(22.5)$ & 70.1 & 40.3 & 20.6-59.9 & & 52.4 & 22.1 & $0-49.1$ & \\
\hline N2 & $52(27.8)$ & 53.9 & 26.6 & $12.1-41$ & & 33.8 & 16.5 & $9-24$ & \\
\hline N3 & $36(29.9)$ & 33.8 & 15.8 & $11.2-20.4$ & 0.001 & 20.1 & 13 & $9.7-16.3$ & $<0.001$ \\
\hline
\end{tabular}


Öven Ustaalioğlu et al.

Gastroesophageal junction tumors according to Siewert classification

Table 2. Univariate analysis results (continued)

\begin{tabular}{|c|c|c|c|c|c|c|c|c|c|}
\hline Properties & $\begin{array}{r}2 \text { yea } \\
\text { number } \mathbf{n}(\%)\end{array}$ & $\begin{array}{l}\text { ar OS } \\
\text { ratio (\%) }\end{array}$ & $\begin{array}{l}\text { Median OS } \\
\text { (month) }\end{array}$ & Margin & $p$ & $\begin{array}{c}2 \text { year DFS } \\
\text { ratio (\%) }\end{array}$ & $\begin{array}{l}\text { Median DFS } \\
\text { (month) }\end{array}$ & Margin & $p$ \\
\hline \multicolumn{10}{|l|}{ Stage } \\
\hline 1 & $13(7)$ & 60.6 & 24.6 & na & & 49.4 & 20.8 & na & \\
\hline 2 & $53(28.3)$ & 80.3 & na & na & & 64.9 & na & na & \\
\hline 3 & $110(58.8)$ & 49.9 & 23.1 & $18.4-27.7$ & & 29.4 & 14.5 & $12-17$ & \\
\hline 4 & $11(5.9)$ & 20 & 15.8 & $10.3-21.3$ & $<0.001$ & 0 & 11.2 & $4.2-18.2$ & $<0.001$ \\
\hline \multicolumn{10}{|l|}{ LI } \\
\hline Absent & $50(26.7)$ & 75 & na & na & & 51.6 & 25.1 & $15.3-34.8$ & \\
\hline Present & $131(70.1)$ & 48.2 & 22.5 & $16.1-28.9$ & 0.004 & 32.1 & 14.5 & $12.5-16.5$ & 0.03 \\
\hline \multicolumn{10}{|l|}{ VI } \\
\hline Absent & $56(29.9)$ & 70 & 22.9 & 20.7-110 & & 5.5 & 27.6 & $11.8-43.4$ & \\
\hline Present & $121(67.4)$ & 49 & 22.5 & $16.4-28.5$ & 0.001 & 30 & 14.5 & $12.4-16.6$ & 0.01 \\
\hline \multicolumn{10}{|l|}{ PNI } \\
\hline Absent & $48(25.7)$ & 69.9 & 17.9 & $10.2-80.8$ & & 61.3 & 38.9 & $7.4-70.4$ & \\
\hline Present & $131(70.1)$ & 50.1 & 3.5 & $17.1-31$ & 0.001 & 29.9 & 14 & $11.7-16.2$ & 0.002 \\
\hline Borrmann c & & & & & & & & & \\
\hline
\end{tabular}

Type 1 (polipoid)

\begin{tabular}{|c|c|c|c|c|c|c|c|c|c|}
\hline Type 2 (fungating) & $3(1.6)$ & na & 19 & na & na & 20.8 & na & & \\
\hline Type 3 (ulcerated) & $4(2.1)$ & 75 & 45.5 & $0-92.8$ & 75 & 38.9 & $0.6-77.2$ & & \\
\hline $\begin{array}{l}\text { Type } 4 \text { (diffuse } \\
\text { infiltrative) }\end{array}$ & $153(81.8)$ & 56.8 & 27.6 & $22.3-32.9$ & 37.7 & 16.4 & $13.2-16.9$ & & \\
\hline Unknown & $10(5.3)$ & 50 & 12.6 & $4-21.1$ & 0.7 & 46.4 & 10.4 & $2.2-18.5$ & 0.2 \\
\hline \multicolumn{10}{|l|}{ Siewert } \\
\hline I & $19(10.1)$ & 38.4 & 19 & $11.8-26.1$ & & 25.7 & 11.3 & $3-19.5$ & \\
\hline II & $40(21.3)$ & 48.1 & 23.1 & $15.5-30.6$ & & 28.6 & 14 & $11-16.9$ & \\
\hline III & $128(68.6)$ & 60.6 & 27.9 & $22.7-33$ & 0.5 & 41.5 & 20.8 & $16.5-29.2$ & 0.08 \\
\hline \multicolumn{10}{|l|}{ Lauren classification } \\
\hline Intestinal & $57(30.5)$ & 76.7 & 29.8 & $23.9-35.6$ & & 47.8 & 21.1 & $10.3-31.9$ & \\
\hline Diffuse & $32(17.1)$ & 52.1 & na & na & & 47 & 15.4 & $2.5-28.3$ & \\
\hline Mixed & $8(4.3)$ & 68.6 & 16.5 & $0-56$ & 0.1 & 34.3 & 17.2 & $7.3-27.1$ & 0.2 \\
\hline \multicolumn{10}{|l|}{ Surgical margin } \\
\hline Positive & $45(24.1)$ & 44.9 & 17.6 & $9.1-26.1$ & & 20.6 & 11.2 & $6.3-16$ & \\
\hline Negative & $142(75.9)$ & 57.3 & 29.8 & $16.9-42.6$ & 0.01 & 42.9 & 22.8 & $15.9-25.6$ & 0.001 \\
\hline \multicolumn{10}{|l|}{ Grade } \\
\hline 1 & $9(4.8)$ & 85.7 & 45.5 & na & & 62.5 & 27.6 & $16.6-38.7$ & \\
\hline 2 & $79(42.2)$ & 60.5 & 27.9 & $14.9-40.8$ & & 36.6 & 20.8 & $14.1-27.4$ & \\
\hline 3 & $93(49.7)$ & 51.2 & 24.1 & $19.1-29$ & $<0.001$ & 38 & 1.5 & $12.8-18.1$ & 0.01 \\
\hline \multicolumn{10}{|l|}{ Neoadjuvant CT } \\
\hline Present & $15(8)$ & 14 & 17.5 & $7.6-27.4$ & & na & 6.6 & $6.2-7.1$ & \\
\hline Absent & $172(92)$ & 58.6 & 27.9 & $21-34.7$ & 0.03 & 40.1 & 17.9 & $13.4-22.4$ & $<0.001$ \\
\hline \multicolumn{10}{|l|}{ Preoperative CT-RT } \\
\hline Present & $14(7.5)$ & 13 & 17.5 & $7.6-27.4$ & & na & 6.6 & $6.1-7.1$ & \\
\hline Absent & $173(92.5)$ & 58.6 & 27.9 & $21-34.7$ & 0.03 & 40.2 & 18 & $14.1-23.9$ & $<0.01$ \\
\hline \multicolumn{10}{|l|}{ Recurrence } \\
\hline Present & $93(49.7)$ & 36.1 & 17.9 & $13.3-22.4$ & & & & & \\
\hline Absent & $94(50.3)$ & 98 & na & na & $<0.001$ & & & & \\
\hline
\end{tabular}

22 LI: lymphatic invasion; VI: vascular invasion; PNI: perineural invasion; CT: chemotherapy; RT: radiotherapy; na: not applicable 
Table 3. Multivariate analysis results

\section{Overall survival Disease-free survival}

\begin{tabular}{lcccc} 
properties & HR & $\mathbf{p}$ & HR & $\mathbf{p}$ \\
grade & 0.81 & 0.01 & 0.94 & $<0.001$ \\
recurrence & 0.84 & $<0.001$ & & \\
\hline Surgical margin & & & 0.30 & 0.009 \\
\hline Preop CT-RT & & & 0.59 & 0.02 \\
\hline
\end{tabular}

HR: hazard ratio; CT: chemotherapy; RT: radiotherapy

\section{DISCUSSION}

In our study, we evaluated the clinicopathologic features, treatment methods and survival rates of 187 patients with GEJ tumor by grouping them according to the Siewert classification. The T stage of Siewert I tumors was more advanced than the others, and presence of metastasis at the time of diagnosis was higher in group I as compared to the others. However, the overall survival rates were similar in each group. Disease-free survival rate was the longest in Siewert III and the shortest in group I, although not statistically significant.

Leers et al. (2) evaluated the data on 509 GEJ tumor according to their location. Including patient symptoms, they reported that reflux symptoms, Barrett's esophagus, and intestinal metaplasia was more frequent in proximal tumors. Since our patients have been referred to our clinic after surgery, we could not evaluate their symptoms. In their study, the presence of lymph node metastases, $\mathrm{T}$ and $\mathrm{N}$ stages were similar between the groups while in our study, T stage, pathologic stage, and Lauren diffuse classification was higher in proximal tumors. The OS, DFS, and recurrence patterns were not different between groups, as in our study. Systemic recurrence and the most common liver metastasis rates were around $25 \%$ in their study like the $20 \%$ rate in our study.

Bai et al. (10) evaluated 203 GEJ tumor according to the Siewert classification, and they reported 29 type I, 80 type II, and 94 type III patients. Type I tumors were also less frequent in our study. Unlike Western societies, in our community similar to the Asian race, this finding may be due to the relatively less frequent occurrence of Barrett's esophagus and intestinal metaplasia. An et al. (12) compared 251 cardia tumors with other gastric tumors, and reported that cardia tumors were at more advanced stages and that the 5-year survival rate during 40-months follow-up was 79.7\%. They also found lymph node metastasis as an independent risk factor for DFS. Our followup period of 13.9 months is the most obvious limiting factor in our study. However, our study is noteworthy not only for including GEJ tumors alone but also for evaluating the differences according to their location and prognosis. In our study group, the median OS was found as 26.6 months. Since our follow-up period is short, the 2-year OS rate, rather than 5 years, was determined as $55.9 \%$. The shorter survival rate may be due to the surgical technique as well as diagnosis of symptomatic patients at more advanced stages.

In a study evaluating the impact of tumor location on survival in GEJ tumors according to the SEER data, 1474 distal esophageal tumors were compared with 192 cardia tumors and no survival difference was reported (21). Feith et al. (7) detected a better survival rate in type I and II tumors as compared to type III tumors. In our series, there was no difference in survival between the three groups, although type I tumors were more aggressive and had more advanced stages. However, type III tumors tended to have a better DFS. This difference may be related to differences in surgical operations performed in our population and in different centers. Distal esophagectomy and subtotal gastrectomy with D1 lymph node dissection was preferred for surgery in proximal tumors, while total gastrectomy and D2 or D3 lymph node dissection was favored more in type 3 tumors.

It is recommended that Siewert I tumors should be staged and treated as esophageal cancer while III tumors as gastric cancer (1). Rüdiger Siewert et al. (4) has shown that esophagectomy does not provide an advantage over extended gastrectomy in type II tumors. Only 67 of our cases had esophagectomy, 24 of which were total and the remaining distal esophagectomies, and no survival benefit was detected in accordance with the literature.

The presence of lymph node metastasis, T stage, N stage, gender, grade, and surgical margin have been shown as independent prognostic factors in GEJ tumors (22). Similar to the literature, stage and grade were independent factors for OS, while grade and surgical margin were associated with DFS. In addition, presence of recurrence was found as an independent risk factor for OS, and preoperative chemoradiotherapy for DFS.

\section{CONCLUSION}

Our study is important since it assesses differences in clinicopathologic features and survival according to location in GEJ tumors alone, and because it reflects our population and treatment approaches, despite the short follow-up period and limited number of patients.

Ethics Committee Approval: Authors declared that the research was conducted according to the principles of the World Medical Association Declaration of Helsinki "Ethical Principles for Medical Research Involving Human Subjects", (amended in October 2013).

Informed Consent: Written informed consent was obtained from patient who participated in this study.

Peer-review: Externally peer-reviewed.

Author Contributions: Concept - B.B.O.U.; Design - B.B.O.U., M.T., A.S.; Supervision - A.B.; Resource - C.G., A.S.; Materials - M.T., A.S., R.U.; Data Collection - B.B.O.U., R.U.; Analysis and/or Interpretation - R.U., A.B.; Literature Search - Ö.B., M.A.; Writing Manuscript - B.B.O.U.; Critical Reviews - C.G.

Conflict of Interest: No conflict of interest was declared by the authors.

Financial Disclosure: The authors declared that this study has received no financial support.

\section{REFERENCES}

1. Fox MP, van Berkel V. Management of gastroesophageal junction tumors. Surg Clin North Am 2012; 92: 1199-1212. [CrossRef]

2. Leers JM, DeMeester SR, Chan N, Ayazi S, Oezcelik A, Abate E, et al. Clinical characteristics, biologic behavior, and survival after esophagectomy are similar for adenocarcinoma of the gastroesophageal junction and the distal esophagus. J Thorac Cardiovasc Surg 2009; 138: 594-602. [CrossRef] 
3. Siewert JR, Stein H. Adenocarcinoma of the gastroesophageal junction: classification, pathology and extent of resection. Dis Esophagus 1996: 9: 173-182.

4. Rüdiger Siewert J, Feith M, Werner M, Stein HJ. Adenocarcinoma of the esophagogastric junction: results of surgical therapy based on anatomical/topographic classification in 1,002 consecutive patients. Ann Surg 2000; 232: 353-361. [CrossRef]

5. Kleinberg L. Therapy for locally advanced adenocarcinoma of the gastroesophageal junction: optimizing outcome. Semin Radiat Oncol 2013; 23: 38-50. [CrossRef]

6. Johansson J, Djerf P, Oberg S, Zilling T, von Holstein CS, Johnsson $F$, et al. Two different surgical approaches in the treatment of adenocarcinoma at the gastroesophageal junction. World J Surg 2008; 32: 1013-1020. [CrossRef]

7. Feith M, Stein HJ, Siewert JR. Adenocarcinoma of the esophagogastric junction: surgical therapy based on 1602 consecutive resected patients. Surg Oncol Clin N Am 2006; 15: 751-764. [CrossRef]

8. Okholm C, Svendsen LB, Achiam MP. Status and prognosis of lymph node metastasis in patients with cardia cancer - a systematic review. Surg Oncol 2014; 23: 140-146. [CrossRef]

9. Westerterp M, Koppert LB, Buskens CJ, Tilanus HW, ten Kate FJ, Bergman JJ, et al. Outcome of surgical treatment for early adenocarcinoma of the esophagus or gastro-esophageal junction. Virchows Arch 2005; 446: 497-504. [CrossRef]

10. Bai JG, Lv Y, Dang CX. Adenocarcinoma of the Esophagogastric Junction in China according to Siewert's classification. Jpn J Clin Oncol 2006; 36: 364-367. [CrossRef]

11. Gronnier C, Piessen G, Mariette C. Diagnosis and treatment of non-metastatic esophagogastric junction adenocarcinoma: what are the current options? J Visc Surg 2012; 149: e23-33. [CrossRef]

12. An JY, Baik YH, Choi MG, Noh JH, Sohn TS, Bae JM, et al. The prognosis of gastric cardia cancer after R0 resection. Am J Surg 2010; 199: 725-729. [CrossRef]

13. Abate E, DeMeester SR, Zehetner J, Oezcelik A, Ayazi S, Costales $J$, et al. Recurrence after esophagectomy for adenocarcinoma: defining optimal follow-up intervals and testing. J Am Coll Surg 2010; 210: 428-435. [CrossRef]
14. Khushalani NI. Cancer of the esophagus and stomach. Mayo Clin Proc 2008; 83: 712-722. [CrossRef]

15. Macdonald JS, Smalley SR, Benedetti J, Hundahl SA, Estes NC, Stemmermann GN, et al. Chemoradiotherapy after surgery compared with surgery alone for adenocarcinoma of the stomach or gastroesophageal junction. N Engl J Med 2001; 345: 725-730. [CrossRef]

16. Cunningham D, Allum WH, Stenning SP, Thompson JN, Van de Velde CJ, Nicolson M, et al. MAGIC Trial Participants. Perioperative chemotherapy versus surgery alone for resectable gastroesophageal cancer. N Engl J Med 2006; 355: 11-20. [CrossRef]

17. Walsh TN, Noonan N, Hollywood D, Kelly A, Keeling N, Hennessy TP. A comparison of multimodal therapy and surgery for esophageal adenocarcinoma. N Engl J Med 1996; 335: 462-627. [CrossRef]

18. Stahl M, Walz MK, Stuschke M, Lehmann N, Meyer HJ, RieraKnorrenschild J, et al. Phase III comparison of preoperative chemotherapy compared with chemoradiotherapy in patients with locally advanced adenocarcinoma of the esophagogastric junction. J Clin Oncol. 2009; 27: 851-856. [CrossRef]

19. Goodman KA. Esophagogastric junction carcinoma: Introduction, Semin Radiat Oncol 2013; 23: 1-2. [CrossRef]

20. Rice TW, Rusch VW, Ishwaran H, Blackstone EH; Worldwide Esophageal Cancer Collaboration. Cancer of the esophagus and esophagogastric junction: data-driven staging for the seventh edition of the American Joint Committee on Cancer/International Union Against Cancer Cancer Staging Manuals. Cancer 2010; 116: 37633773. [CrossRef]

21. Whitson BA, Groth SS, Li Z, Krtazke RA, Maddaus MA. Survival of patients with distal esophageal and gastric cardia tumors: A population-based analysis of gastroesophageal jinction carcinomas. J Thorac Cardiovasc Surg 2010; 139: 43-48. [CrossRef]

22. Mariette C, Castel B, Balon JM, Van Seuningen I, Triboulet JP. Extent of oesophageal resection for adenocarcinoma of the oesophagogastric junction. Eur J Surg Oncol 2003; 29: 588-593. [CrossRef] 